\title{
Delimitação de áreas inundáveis a partir de Modified Normalized Difference Water Index (MNDWI) no Município de Esteio (RS, Brasil)
}

\author{
João Paulo BRUBACHER ${ }^{1}$, Laurindo Antonio GUASSELLI ${ }^{1}$ \& Guilherme Garcia de OLIVEIRA²
}

1 Programa de Pós-Graduação em Sensoriamento Remoto, Universidade Federal do Rio Grande do Sul. Av. Bento Gonçalves, 9.500, CEP 91.540-000, Porto Alegre, RS, Brasil (jp.brubacher@hotmail.com, laurindo.guasselli@ufrgs).

2 Programa de Pós-Graduação em Sistemas Ambientais Sustentáveis, Centro Universitário Univates. Rua Avelino Talini, 171, Bairro Universitário, CEP 95.900-000, Lajeado, RS, Brasil (guilherme.oliveira@univates.br).

Recebido em 06/2016. Aceito para publicação em 07/2017.

Versão online publicada em 21/10/2017 (www.pesquisasemgeociencias.ufrgs.br)

\begin{abstract}
Resumo - Uma das possibilidades de análise a partir de imagens de satélite é a variação espacial e temporal de comportamento de áreas inundáveis. Entre os índices desenvolvidos para análise de recursos hídricos, se destaca o Modified Normalized Difference Water Index (MNDWI), elaborado com o intuito de ressaltar áreas inundáveis com um maior poder de discriminação dos alvos. Esse trabalho tem como objetivo verificar a dinâmica espacial e temporal das inundações, utilizando imagens LANDSAT para observar o extravasamento das águas do Rio dos Sinos, a partir do índice MNDWI, como subsídio para a delimitação de inundações no município de Esteio, localizado na Região Metropolitana de Porto Alegre, Rio Grande do Sul, Brasil. Para tanto, foram utilizadas quatro datas de imagens selecionadas a partir da leitura da precipitação acumulada de dez e trinta dias: 30/08/1984 e 30/03/2004 (baixa precipitação), 19/11/1990 e 01/10/2007 (precipitação acumulada mais alta). As duas primeiras datas apresentaram precipitação média acumulada de 113,6 e 61,5 mm, no período de 30 dias e 19,7 mm e 11,9 mm, no período de 10 dez dias anteriores à aquisição da imagem. As datas de 19/11/1990 e 01/10/2007 apresentaram, respectivamente, $201.7 \mathrm{~mm}$ e $200.1 \mathrm{~mm}$ acumulados no período de 30 dias e 28.1 e $126.6 \mathrm{~mm}$ acumulados no período de 10 dias anteriores à imagem. Em relação às manchas de inundação, nas imagens com baixo acúmulo de precipitação, as médias de MNDWI ficaram em -0,33, ou seja, bem mais baixo em relação a 01/10/2007, com uma média de -0,11. Esse dado pode ser percebido principalmente nos pontos onde a mancha de inundação foi separada da composição MNDWI e sobreposta na imagem do município, propiciando o estudo da influência dessa inundação no escoamento dos arroios que cortam o município de Esteio.
\end{abstract}

Palavras-chave: desastres, inundação, imagens de satélite

Abstract - DELIMITATION OF FLOODPLAINS FROM MODIFIED NORMALIZED DIFERENCE WATER INDEX (MNDWI) IN THE CITY OF ESTEIo (RS, BRASIL). One of the possibilities of analysis from satellite images is the spatial and temporal variation of flodplains. Among the indices developed for analysis of water resources highlights the Modified Normalized Difference Water Index (MNDWI), prepared in order to highlight flood areas with a higher power of discrimination of targets. This work aims to verify the spatial and temporal dynamics of floods, using Landsat images to observe the overflow of water from the Sinos River, from MNDWI index, as support for the delimitation of flooding in the city of Esteio, located in the Metropolitan Region of Porto Alegre, Rio Grande do Sul, Brazil. Therefore, we used four dates of selected images from the reading of accumulated rainfall of ten and thirty days: 08/30/1984 and 03/30/2004 (low rainfall), 11/19/1990 and 10/01/2007 (highest accumulated rainfall). The first two dates showed average accumulated rainfall of $113.6 \mathrm{~mm}$ and $61.5 \mathrm{~mm}$, within 30 days and $19.7 \mathrm{~mm}$ and $11.9 \mathrm{~mm}$, within 10 days preceding ten image acquisition. The dates of 11/19/1990 and 10/01/2007 presented, respectively, $201.7 \mathrm{~mm}$ and $200.1 \mathrm{~mm}$ accumulated in the period of 30 days and 28.1 and $126.6 \mathrm{~mm}$ accumulated in the previous 10 days of the image acquisition. Concerning the analysis of flood spots in images with low accumulation of precipitation, average MNDWI stood at -0.33 , that is lower in relation to the date $10 / 01 / 2007$, with a mean of -0.11 . This data can be seen mainly in points where flood spot was separated from MNDWI composition and overlaps on the city's image, allowing the study of the influence of this flood in the flow of the streams that cutting through the city of Esteio.

Keywords: disasters, floods, LANDSAT satellite 


\section{Introdução}

A partir de técnicas de processamento de imagens de satélite, é possível analisar a dinâmica da variação temporal e espacial do comportamento de áreas de inundação. Jackson et al. (2004), Lopes et al. (2014) e Albuquerque et al. (2014), por exemplo, utilizaram sensoriamento remoto para estudar os recursos hídricos no âmbito qualidade da água, períodos de secas e inundações.

O uso dessas técnicas na temática de desastres provocados pelo extravasamento de cursos de água (Londe et al., 2014; Sausen \& Lacruz, 2015) também possibilita a determinação de canais e lagos com a utilização de índices espectrais (Morais, 2010; Brenner \& Guasselli, 2015; Re et al., 2015; Saavedra et al., 2015; Brubacher, 2016).

Os índices espectrais são medidas radiométricas adimensionais, resultantes de operações matemáticas entre valores numéricos dos pixels de bandas de imagens obtidas por sensoriamento remoto. O NDVI (Índice de Vegetação por Diferença Normalizada), desenvolvido por Rouse et al. (1973), visa a análise da vegetação, normalizando uma razão simples, utilizando as bandas do vermelho e do infravermelho próximo, de modo a realçar o comportamento espectral da vegetação (Epiphanio et al., 1996; Govaerts \& Verhulst, 2010).

O NDWI (Índice de Diferença Normalizada de Água), proposto por McFeeters $(1996,2013)$, utiliza as bandas do verde e do infravermelho próximo, com objetivo de maximizar a reflectância de água, por meio da utilização da banda verde, minimizar a baixa reflexão dos corpos de água pelo infravermelho próximo e tirar proveito da alta reflexão da vegetação e do solo no infravermelho médio.

Um dos problemas apontados por Xu (2006), em relação ao NDWI, se refere às informações hídricas extraídas de áreas que apresentam, além de água, vegetação e zonas urbanizadas. Nesse caso, corre-se o risco que essas informações se misturem com os ruídos das áreas ao entorno. Dessa forma, Xu (2006) modificou o índice proposto por McFeeters (1996), criando o MNDWI (Índice de Diferença Normalizada de Água Modificada), substituindo a utilização do infravermelho próximo pelo infravermelho médio.

Para mapear e monitorar os recursos hídricos superficiais e a dinâmica hídrica, Ji et al. (2009) analisaram diversos sensores e comprimentos de onda, e avaliaram qual equação de NDWI obtinha melhores resultados visando a determinação de corpos hídricos. Utilizando imagens LANDSAT TM, os limiares mais estáveis foram obtidos a partir da razão entre as bandas do verde e do infravermelho médio, o mesmo do MNDWI desenvolvido por Xu (2006).

A utilização desses índices pode ter uma contribuição importante na análise de desastres provocados por inundações, mesmo levando-se em conta a baixa resolução temporal (16 dias) e as dificuldades em mapear o pico das inundações devido à cobertura de nuvens.

Os municípios localizados na bacia hidrográfica do Rio dos Sinos têm sido frequentemente acometidos por inundações (Oliveira et al., 2009; Bazzan, 2011; Penteado et al., 2012). Principalmente nos últimos anos, o Município de Esteio (Brubacher, 2016) tem enfrentado fortes precipitações e o consequente extravasamento das águas tanto do Rio dos Sinos, quanto dos arroios Esteio e Sapucaia, que cortam o município.

No entanto, a falta de séries históricas de precipitação dificulta a análise temporal das inundações no município. As imagens de satélite disponíveis não permitem identificar as manchas de inundação de pequenas bacias. Trata-se de uma restrição relativa à resolução espacial das imagens LANDSAT, o que prejudica a previsão e o mapeamento das áreas mais afetadas.

Apesar desse fato, a ampla área de várzea do Rio dos Sinos serve como identificador das grandes inundações que afetam o município. Dependendo das condições climáticas, da direção do vento e do nível de inundação no rio, as águas dos arroios Esteio e Sapucaia não conseguem escoar e inundam a área urbana do município.

Esse trabalho tem como objetivo verificar a dinâmica espacial e temporal das inundações, utilizando imagens LANDSAT para observar o extravasamento das águas do Rio dos Sinos, a partir do índice MNDWI, como subsídio para a delimitação de inundações no município de Esteio, RS.

\section{2 Área, materiais e métodos}

\section{1 Área de estudo}

A bacia do Rio dos Sinos está localizada no nordeste do estado do Rio Grande do Sul e possui uma área total de $3.820 \mathrm{~km}^{2}$. Essa bacia é uma das mais importantes do estado, inserida na Região Metropolitana de Porto Alegre, com uma população total de cerca de 1,3 milhões de habitantes. 0 Rio dos Sinos tem em seus principais afluentes os rios Paranhana e Rolante, com as suas nascentes concentradas nos municípios de Gramado, Canela e Caraá.

Esteio se localiza na porção do baixo Rio dos 
Sinos, cerca de $10 \mathrm{~km}$ da foz da bacia (Fig. 1), possui área urbana de $18,6 \mathrm{~km}^{2}$ e população de 83.846 habitantes (IBGE, 2014), o que o qualifica como a maior densidade demográfica do Estado do Rio Grande do Sul, totalizando 2.917,87 hab $/ \mathrm{km}^{2}$. Em sua porção oeste, uma área de cerca de $9 \mathrm{~km}^{2}$ se refere à área rural (Fig. 2).

De acordo com o zoneamento do município, essa área é considerada como "várzea do Rio dos
Sinos", e concentra a pequena produção agrícola do município. Segundo IBGE (2014), a produção de arroz é de 1,47 t. Esteio possui uma importante divisão territorial, imposta por meio da construção da BR 116 e do Trensurb (Empresa de Trens Urbanos de Porto Alegre S.A.), que praticamente dividem a área mais urbanizada do município, a leste da rodovia, e a várzea do Rio dos Sinos, a oeste (Fig. 2).
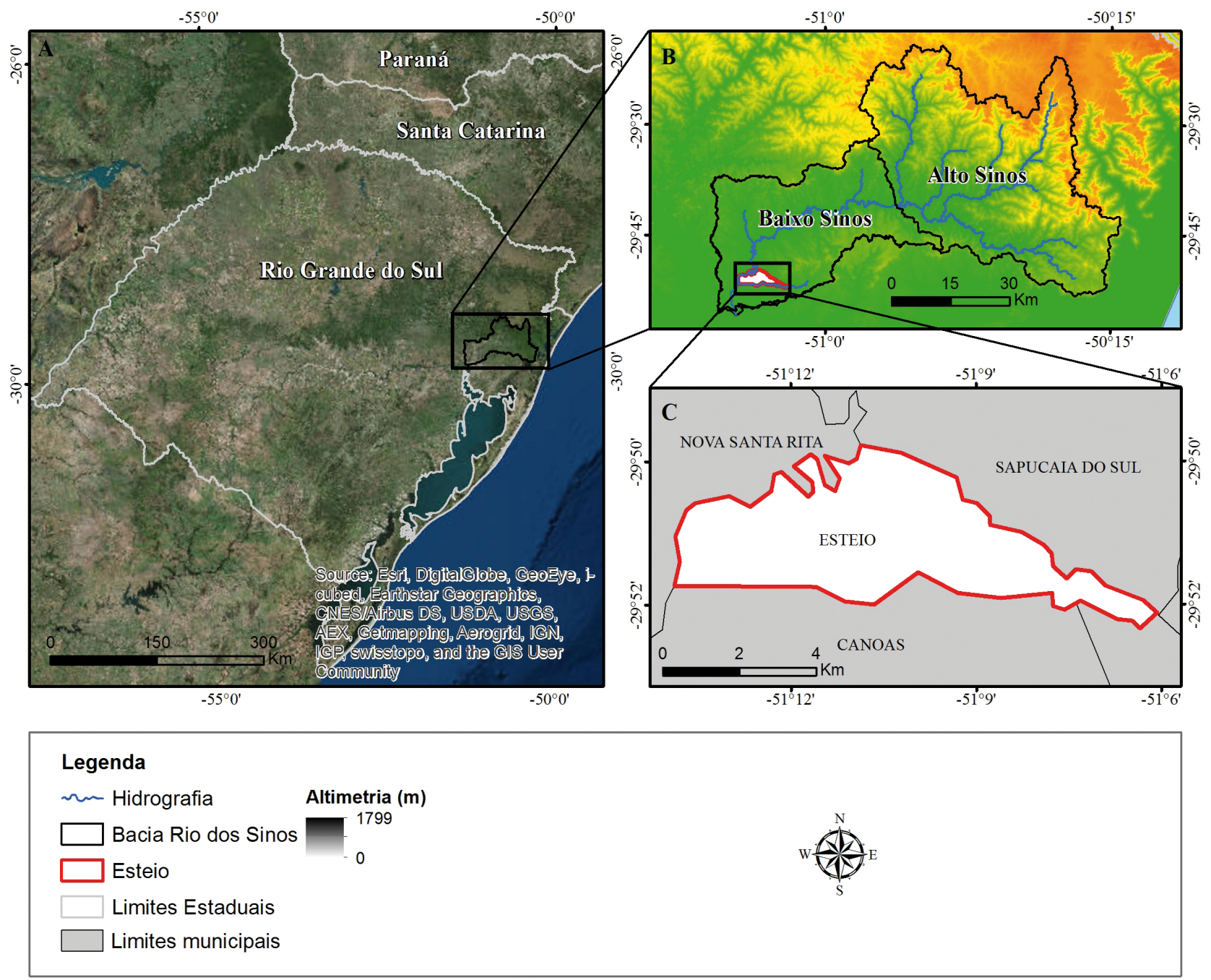

Figura 1. Mapa de localização. A) Bacia hidrográfica do Rio dos Sinos em relação ao Estado do Rio Grande do Sul; B) Localização de Esteio em relação a bacia e altimetria da bacia do Rio dos Sinos; C) Municípios que fazem divisa com Esteio.

Figure 1. Location map. A) Sinos River basin over the Rio Grande do Sul state; B) Localization of Esteio over the basin and altimetry of the Sinos River basin; C) Municipalities that border with Esteio.

Esteio está inserido na sub-bacia do arroio Sapucaia, com planície de inundação altamente urbanizada regularmente atingida por inundações, e o arroio Esteio, que foi ligado ao arroio Sapucaia, com o intuito de diminuir as inundações. Na área oeste do município, próximo ao Rio dos Sinos (Fig. 2), predominam pequenos canais voltados para a irrigação das lavouras de arroz. 

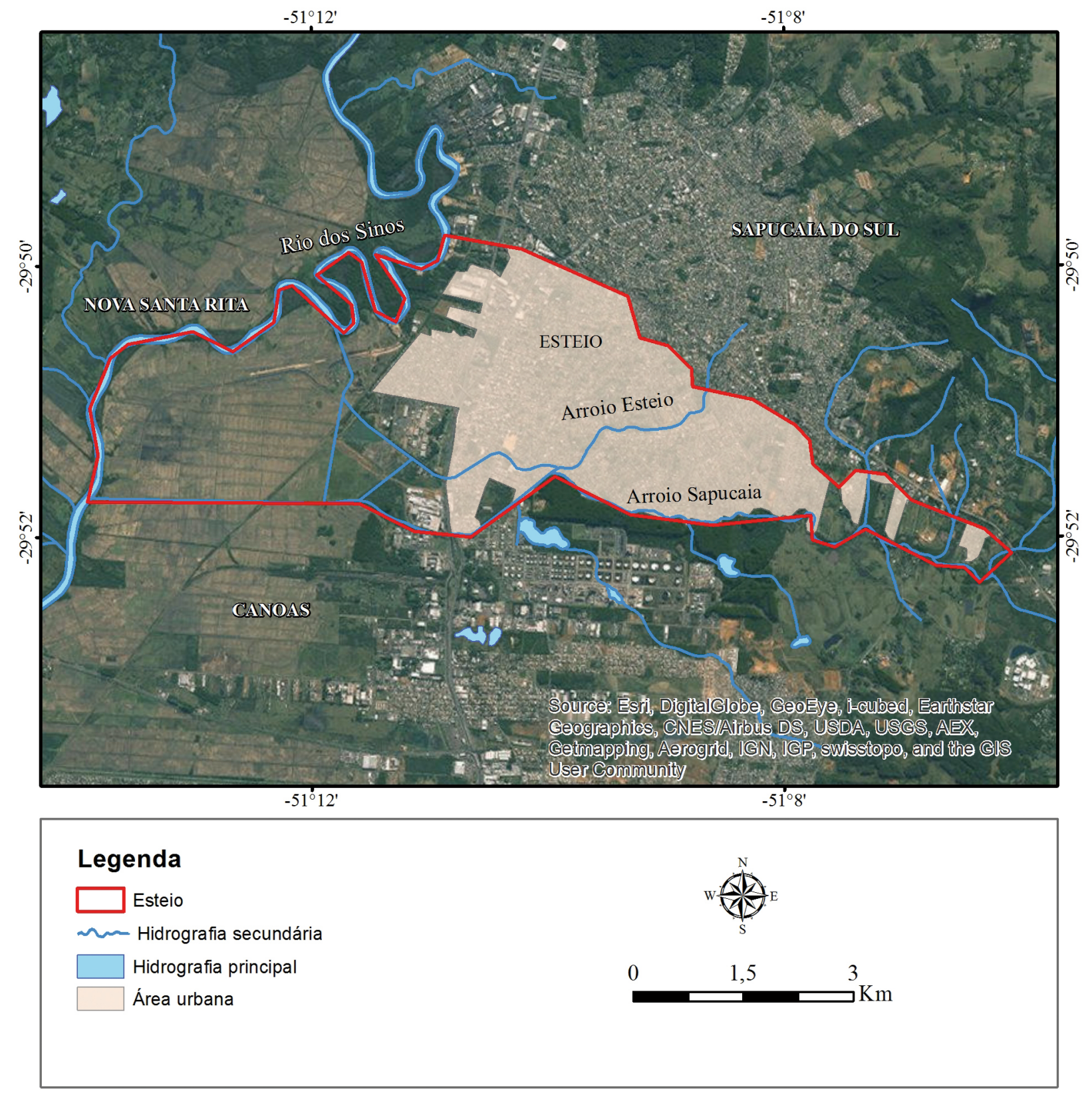

Figura 2. Hidrografia e indicação da área urbana do Município de Esteio, RS.

Figure 2. Hidrography and indications of urban area of Municipality of Esteio, RS.

\subsection{Materiais e métodos}

Foram utilizadas imagens do sensor Landsat-5/TM, órbita/ponto 221/081, nas seguintes 30/08/1984, 19/11/1990, 3/03/2004 e 01/10/2007, obtidas no catálogo de imagens do Instituto Nacional de Pesquisas Espaciais (INPE). Essas datas foram escolhidas levando em conta a cobertura de nuvens, a precipitação em um período de 30 dias e a situação da várzea dos Sinos na data de aquisição da imagem.

Visando a análise pluviométrica local, foi utilizada uma série histórica de dados de precipitação interpolados para a bacia hidrográfica do Rio dos Sinos por Brubacher et al. (2012). Para chegar a esses dados, o autor utilizou somente séries com mais de 15 anos completos de registros, obtidas por meio do portal HIDROWEB, da Agência Nacional de Águas, num raio de $100 \mathrm{~km}$ da bacia, totalizando 34 séries pluviométricas. A interpolação espacial, desenvolvida no MATLAB (MATrix LABoratory), foi realizada em uma grade regular, com resolução espacial de $5 \mathrm{~km}$, totalizando 150 nós, visando analisar a precipitação no Município de Esteio. 0 método em questão para análise pluviométrica foi necessário devido à falta de uma estação no município que compreendesse um largo período de tempo.

A imagem de 01/10/2007 compreende um 
período relativamente úmido, com precipitação nos 30 dias antecedentes de 200,1 mm, enquanto a média para o mês de setembro é de $146 \mathrm{~mm}$, relativo à normal climatológica. Na data de aquisição da imagem, a régua linimétrica com cota fluviométrica em São Leopoldo, cerca de $12 \mathrm{~km}$ de Esteio, chegou a $5 \mathrm{~m}$. Nesse momento, o rio já estava baixando, após seis dias acima desse nível. Esse limiar, de acordo com Bazzan (2011), é suficiente para provocar inundações na várzea do Rio dos Sinos.

A imagem de 19/11/1990 também se refere a um período relativamente úmido, com precipitação acumulada nos 30 dias anteriores de 201,7 $\mathrm{mm}$, enquanto a média histórica para o mês de novembro é de $113 \mathrm{~mm}$. Já para as imagens de 30/08/1984 e 30/03/2004, a precipitação para os 30 dias anteriores foi de $113,6 \mathrm{~mm}$ e $61,5 \mathrm{~mm}$, respectivamente. Nesses dois casos, a média para o mês de agosto é de 136,8 mm e para março é de $101,74 \mathrm{~mm}$.

Na etapa de pré-processamento, as imagens foram processadas no software ArcGIS10.3, georreferenciadas e exportadas para o formato 32 Bits Float, para que os resultados da álgebra de bandas no software pudessem apresentar índices espectrais em valores decimais no intervalo entre $-1 \mathrm{e}$ +1 .

Segundo Ji et al. (2009), o índice espectral para determinação de água é um número único, derivado de uma operação aritmética (que pode ser proporção, diferença ou diferença normalizada) de duas ou mais bandas espectrais. A concepção de um índice espectral de água foi baseada no fato de que a água absorve energia em comprimentos de onda do infravermelho próximo (NIR/ IVP) e ondas curtas de infravermelho (SWIR/IVM). Além de melhorar os sinais espectrais, contrastando a reflectância entre diferentes comprimentos de onda, também é capaz de diminuir ruídos nas imagens, muitas vezes causados por iluminação, topografia e condições atmosféricas.

Adotando o formato de diferença normalizada da vegetação (NDVI), McFeeters (1996) desenvolveu o índice de água por diferença normalizada como (Equação 1):

NDWI $=($ pverde - pIVP) $/($ pverde + pIVP $)$

(Equação 1)

Em que: pverde é a banda de reflectância do verde, e pIVP do infravermelho próximo.

0 solo e a vegetação possuem reflectância similar nas bandas do verde e do vermelho. A razão para o uso da banda verde, em vez da banda do vermelho, é que a reflectância da vegetação é mais alta na banda do verde, devido à absorção de clorofila, de modo que a banda do verde é relativamente insensível aos componentes de fundo.

$\mathrm{Xu}$ (2006) observou que McFeeters (1996) não foi capaz de separar completamente as demais características do terreno em relação aos recursos hídricos. O NDWI proposto por McFeeters apresenta valores positivos em características construídas que eram semelhantes à água, porque a reflectância do IVP foi menor do que a reflectância da banda do verde. Para compensar as desvantagens do NDWI de McFeeters, Xu (2006) propôs substituir a faixa do IVP pela faixa do IVM, gerando o MNDWI (Equação 2).

MNDWI $=($ pverde - pIVM $) /($ pverde + pIVM $)$ (Equação 2)

Em que: pverde é a banda de reflectância do verde, e pIVM do infravermelho médio.

Devido à relevante diferença entre a área leste (mais urbanizada) e a oeste do município (várzea do Rio dos Sinos), foi estabelecida uma máscara para a área de várzea, de forma que o cálculo da média do MNDWI não fosse tão influenciado pela área ao leste da BR 116.

\section{Resultados e discussão}

A partir das imagens de MNDWI e da precipitação acumulada de 10 e 30 dias foram calculados os valores médios para a área do Município de Esteio e para a máscara da parte oeste do município que contém a área de várzea do Rio dos Sinos (Tab. 1).

Tabela 1. Médias de MNDWI e precipitação acumulada em 5 e 30 dias em Esteio, RS. Table 1. Average NDVI and accumulated rainfall at 5 and 30 days em Esteio, RS.

\begin{tabular}{lccccc}
\hline \multicolumn{1}{c|}{ DATA } & $30 / 08 / 1984$ & $30 / 03 / 2004$ & $19 / 11 / 1990$ & $01 / 10 / 2007$ \\
\hline MNDWI Médio na área do município & $-0,33$ & $-0,33$ & $-0,31$ & $-0,11$ \\
NDPI Médio na área de várzea & $-0,31$ & $-0,31$ & $-0,29$ & 0,19 \\
Precipitação acumulada (mm) 5 dias & 19,7 & 11,9 & 28,1 & 126,6 \\
Precipitação acumulada (mm) 30 dias & 113,6 & 61,5 & 201,7 & 200,1 \\
\hline
\end{tabular}


Os resultados (Tab.1) apontam que nas datas de 30/08/1984 e 30/03/2004 o valor médio de MNDWI foi de -0,33 para a área do município, e de -0,31, para a área de várzea, dados compatíveis com os valores encontrados por Xu (2006) para áreas úmidas. Estas duas datas têm em comum a baixa precipitação acumulada tanto no período de cinco dias quanto no período de 30 dias anteriores a imagem, bem abaixo da média mensal para ambos os meses, que costuma ser de $144 \mathrm{~mm}$ em agosto e $131 \mathrm{~mm}$ em março.

Para as datas 19/11/1990 e 01/10/2007, as precipitações no período de 10 dias anteriores à aquisição das imagens foram de $28,1 \mathrm{~mm}$ e de $126,6 \mathrm{~mm}$, respectivamente. Ao se considerar o período de 30 dias anteriores à imagem, esse valor sobe para 201,7 mm e 200,1 mm, respectivamente.

As duas datas possuem uma média de chuvas para 30 dias acima dos valores médios mensais para os meses de setembro e novembro (146 e $113,4 \mathrm{~mm}$, respectivamente). Na data de aquisição da imagem de $01 / 10 / 2007$, a régua linimétrica no Município de São Leopoldo, localizado a cerca de $14 \mathrm{~km}$ a montante de Esteio, marcava $5 \mathrm{~m}$, valor suficiente para causar inundações na região (Bazzan, 2011).

Embora a precipitação acumulada em cinco dias para a data 01/10/2007 não tenha sido alta, a precipitação acumulada nas cabeceiras da bacia do Rio dos Sinos pode ter influenciado para que na referida data o rio tivesse acima do nível normal. 0 valor médio de MNDWI para a data de 19/11/1990 foi de $-0,31$ e para a data de $01 / 10 / 2007$ foi de $-0,11$.

O valor médio de MNDWI se sobressai, principalmente, quando é considerada apenas a região da área de várzea do Rio dos Sinos. 0 valor médio de MNDWI chega a 0,19 no dia $01 / 10 / 2007$, o que ressalta a grande influência do acúmulo de água na área de várzea.

A figura 3 mostra a composição de MNDWI das imagens dos dias 30/08/1984 (A), 30/03/2004 (B), $19 / 11 / 1990$ (C) e 01/10/2007 (D). A imagem representa os corpos de água e áreas inundáveis com valores médias mais próximos a 1 , enquanto os outros componentes do solo apresentam valores mais próximos de -1 .

Nas imagens de 30/08/1984 e 30/03/2004, período relativamente seco, praticamente não se observa áreas de acúmulo de água, a não ser nos meandros perenes do Rio dos Sinos. Esse fato se reflete nos valores de MNDWI, com um valor de $-0,33$, considerando todo o município e $-0,31$, considerando apenas a várzea.

A figura 3 apresenta as quatro imagens re- presentam o índice MNDWI, sendo duas com baixa precipitação acumulada em 30 dias e duas com precipitação mais elevada. 0 contraste entre as imagens é perceptível, principalmente, na imagem relativa a 01/10/2007. Embora as precipitações acumuladas em 30 dias sejam semelhantes em $01 / 10 / 2007$ e em 19/11/1990, entre os dias 22 e 27 de setembro de 2007, grandes precipitações assolaram a região, causando inundações, inclusive, nas bacias adjacentes à bacia dos Sinos. Nos 10 dias anteriores à imagem de 19/11/1990, a precipitação não foi suficiente para causar inundações. Outros trabalhos comprovam a possibilidade de utilizar o índice MNDWI para delimitação de áreas inundadas e reconhecimento de corpos de água (Gonzaga et al., 2011; Ariza et al., 2014; Saavedra et al., 2015; Reis \& Saavedra, 2015).

Um dos fatores importantes ao se comparar as imagens da figura 3 com os resultados da tabela 1 se refere ao valor do MNDWI médio, bastante superior na imagem do dia 01/10/2007 (média de 0,19 na área de várzea) em relação às demais imagens. Esse contraste permite visualizar uma extensa área escura na porção oeste, que representa a influência do extravasamento do rio para o acúmulo de água na área de várzea. A mancha de inundação é compatível com o que foi apresentado por Oliveira (2007) e Bazzan (2011), para o Rio dos Sinos.

A data de 19/11/1990 apresenta um acúmulo semelhante de precipitação para o período de 30 dias; no entanto, nos 10 dias anteriores a aquisição da imagem, a precipitação acumulada de $28,1 \mathrm{~mm}$ não foi o suficiente para causar inundações.

As imagens de 30/08/1984 e 30/03/2004, por outro lado, apresentaram o esperado, ou seja, praticamente não se observam áreas de acúmulo de água, a não ser nos meandros perenes do Rio dos Sinos. Esse fato se reflete nos valores de MNDWI, mais baixos do que nas imagens de 19/11/1990 e 01/10/2007, com uma média de -0.33 .

Na figura 4, está sobreposta a mancha de inundação da data 01/10/2007, na planície de inundação do rio dos Sinos, em relação à área de Esteio e dos municípios vizinhos. É possível ter noção do alcance da mancha, que aparece com cor mais escura na figura 3D.

A mancha de inundação na figura 4 dá a real dimensão do alcance da inundação utilizando a imagem obtida pelo índice MNDWI. Destaca-se a proximidade da mancha com a área urbana de Esteio tem influência direta no escoamento dos arroios Esteio e Sapucaia, principal fonte das inundações da área urbana. 

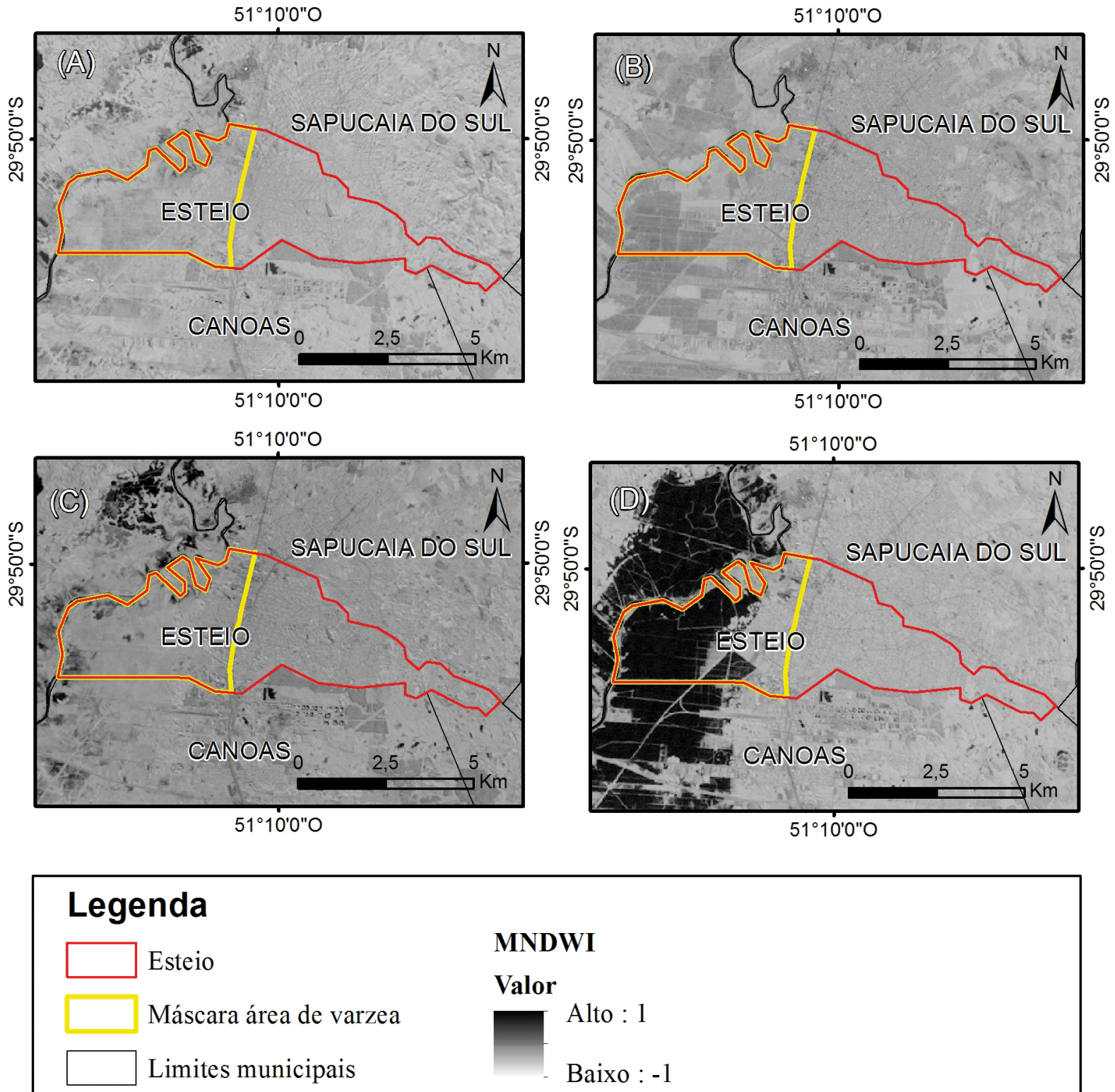

Figura 3. Distribuição espacial de MNDWI para as quatro datas estudadas. A) 30/08/1984; B) 30/03/2004; C) 19/11/1990; D) $01 / 10 / 2007$.

Figure 3. Spatial distribution of MNDWI for the four dates studied. A) 30/08/1984; B) 30/03/2004; C) 19/11/1990; D) 01/10/2007.

0 represamento dos arroios ocorre por fatores principalmente antrópicos, devido à grande urbanização do local, sendo que as condições climáticas, como os ventos soprando do quadrante sul, podem influenciar no escoamento do Rio dos Sinos em direção ao Lago Guaíba, provocando um efeito de remanso das águas.

Por se tratarem de arroios de pequeno porte, torna-se difícil a identificação dos canais dos arroios Esteio e Sapucaia por meio da imagem LANDSAT. O Arroio Sapucaia, por exemplo, apresenta uma variação na sua largura de cerca de 2 a $6 \mathrm{~m}$, e sua vazão média, embora possa variar consideravelmente em eventos extremos de precipitação, fica em torno de $0,45 \mathrm{~m}^{3} / \mathrm{s}$ no ponto anterior a ju- sante do Arroio Guajuviras (que conta com despejo de efluentes da REFAP - Refinaria Alberto Pasqualini); e $0,39 \mathrm{~m}^{3} / \mathrm{s}$ no ponto logo após a foz deste (Franzen et al., 2006).

Por meio da análise dos dados de precipitação é possível perceber entre os dias 22 e 27 de setembro teve um total de $126,2 \mathrm{~mm}$, fato corroborado pelo jornal Correio do Povo em matéria do dia 27, que afirma que a elevação das águas em São Leopoldo chegou a $6 \mathrm{~m}$, o suficiente para causar inundações em diversas localidades da região do baixo Sinos.

Em São Leopoldo, a montante do Rio dos Sinos, a régua linimétrica marcou cinco $\mathrm{m}$ do dia 26/09/2007 ao dia 01/10/2007. No dia da aqui 
sição da imagem o rio já estava recuando, mesmo assim, a mancha de inundação ficou bem definida na várzea do rio (Fig. 4). Embora as chuvas não tenham sido suficientes para causar in- undações na área urbana do município entre os arroios Sapucaia e Esteio, os bairros mais próximos ao Rio dos Sinos (Três Portos e Novo Esteio) foram atingidos pela sua elevação.
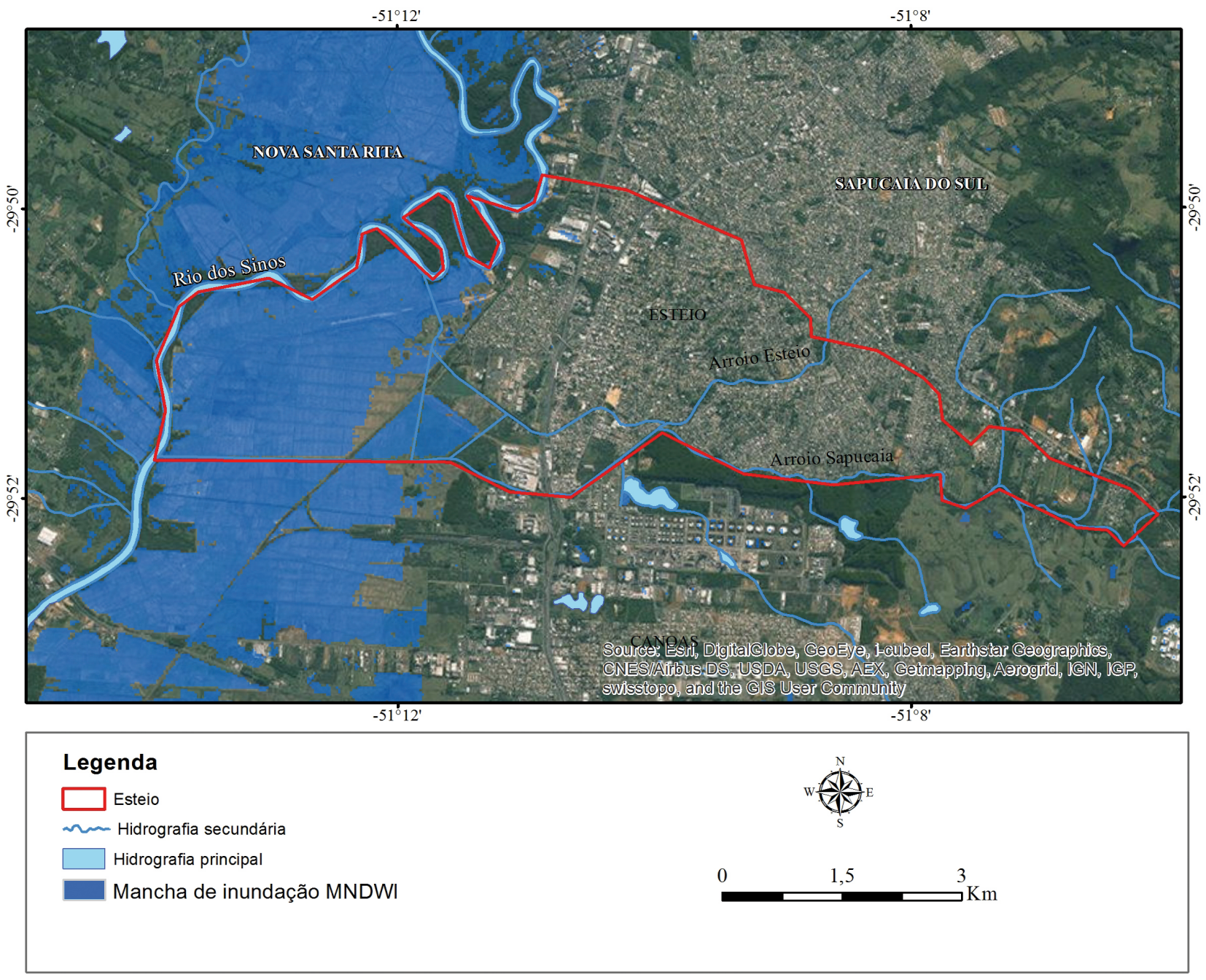

Figura 4. Mancha de inundação a partir de MNDWI em 01/10/2007, Município de Esteio, RS. Figure 4. Flood spot from MNDI on 01/10/2007, Municipality of Esteio, RS.

Para efeitos de comparação, a imagem de $30 / 04 / 2004$, por exemplo, apresenta somente a linha referente ao Rio dos Sinos, ou seja, com toda planície de inundação seca dentro da área do município. A utilização de uma imagem LANDSAT pode, inclusive, ser de grande relevância na delimitação de cursos de água, desde que os mesmos não tenham grandes interferências da vegetação, de modo a não ter a resposta espectral da água alterada pelo efeito dossel.

0 escoamento dos arroios Esteio e Sapucaia em direção ao Rio dos Sinos pode ser afetado em períodos de cheia, provocando o efeito de remanso das águas, fazendo que os mesmos inundem boa parte da região em torno dos arroios. Esse fato, aliado aos pontos de bloqueios encontrados em diversos pontos dos arroios (pontes, drenagem insuficiente e excesso de lixo), é apenas um dos fatores que fazem com que o entorno dos arroios seja suscetível a inundações.

A área do município compreendida pela mancha de inundação é equivalente a $7,76 \mathrm{~km}^{2}$. Mesmo que a maior parte se encontre na área de várzea do Rio dos Sinos, é importante destacar que os pontos de bloqueio que existem em relação aos arroios Sapucaia e Esteio, em conjunto com a área de várzea inundada, auxiliam no efeito de remanso dos arroios, que faz com que as águas não escoem livremente para o rio dos Sinos. 


\section{Conclusões}

Quanto mais ferramentas estiverem disponíveis para utilizar na análise de desastres, menores serão os riscos futuros. A utilização de imagens LANDSAT na área de desastres não é novidade; no entanto, a utilização de índices específicos para identificação de corpos hídricos ainda pode ser melhor explorada.

Em relação à análise das manchas de inundação geradas por meio da razão entre as bandas do verde e do infravermelho médio, foi possível visualizar que nas imagens escolhidas, com base nos baixos acúmulos de precipitação, as médias mais altas dos valores de MNDWI foram mais explícitas, de fato, na imagem do dia 01/10/2007, pressupondo a existência de áreas alagadas.

O MNDWI médio das demais imagens representam as diferenças entre a precipitação nos períodos anteriores à aquisição da imagem e a possibilidade de comparação devido ao resultado obtido na imagem de 01/10/2007.

No momento em que a mancha de inundação foi separada da imagem original e sobreposta à imagem em alta resolução do município, a análise da influência desse evento no escoamento dos arroios que cortam o município de Esteio fica mais compreensível, de modo que os mesmos, apesar de sofrerem grande influência antrópica, tem seu escoamento em direção ao Rio dos Sinos prejudicado quando a planície de inundação se encontra alagada, o extravasando para a área urbanizada da cidade por efeito de remanso.

Agradecimentos. Os autores agradecem a Coordenação de Aperfeiçoamento de Pessoal de Nível Superior (CAPES) pela concessão do auxílio financeiro como Bolsa de Mestrado ao primeiro autor, bem como ao Programa de Pós-Graduação em Sensoriamento Remoto (PPGSR).

\section{Referências}

Albuquerque, E.M., Andrade, S.C.P., H.F.M., Diniz, J.M.T. \& Santos, C.A.C. 2014. Análise do comportamento do NDVI e NDWI sob diferentes intensidades pluviométricas no município de Sousa-PB. Revista Estudos Geoambientais, 01: 1 - 11.

Ariza, A., Sergi Garcia, J., Sergio Rojas, B. \& Mauricio Ramirez, D. 2014. Desarrollo de un modelo de corrección de imágenes de satélite para inundaciones: (CAIN -Corrección Atmosférica e Índices de Inundación). Disponível em <http://docplayer.es/2900781-Desarrollo-de-un-modelo-de-correccion-de-imagenes-de-satelite-para-inundaciones-cain-correccion-atmosferica-e-indices-de-inundacion.html> Acesso em: 08 abr. 2016.
Bazzan, T. 2011. Mapeamento das Áreas com risco de inundação do rio dos Sinos no município de São Leopoldo, RS. Porto Alegre, 135 p. Dissertação de Mestrado, Programa de Pós-Graduação em Geografia, Instituto de Geociências, Universidade Federal do Rio Grande do Sul.

Brenner, V.C. \& Guasselli, L.A. 2015. Índice de diferença normalizada da água (NDWI) para identificação de meandros ativos no leito do canal do rio Gravataí/ RS - Brasil. In: SIMPÓSIO BRASILEIRO DE SENSORIAMENTO REMOTO, 17., 2015, João Pessoa. Anais... João Pessoa. p. 3693-3699. Disponível em: <http:// www.dsr.inpe.br/sbsr2015/files/p0727.pdf>. Acesso em: 18 nov. 2015.

Brubacher, J.P. 2016. Inundações e enxurradas, município de Esteio - RS. Porto Alegre, 110 p. Dissertação de Mestrado, Programa de Pós-Graduação em Sensoriamento Remoto, Universidade Federal do Rio Grande do Sul.

Brubacher, J.P., Oliveira, G.G. \& Guasselli, L.A. 2012. Identificação e análise de eventos extremos de precipitação na bacia hidrográfica do rio dos Sinos/RS. In: CONGRESSO BRASILEIRO DOBRE DESASTRES NATURAIS, 01., 2012, Rio Claro. Anais... Rio Claro. 1 CD-ROM.

Epiphanio, J.C.N., Gleriani, J.M., Formaggio, A.R. \& Rudorff, B.F.T. 1996. Índices de vegetação no sensoriamento remoto da cultura do feijão. Pesquisa Agropecuária Brasileira, 31(6): 445-454.

Franzen, M., Mizusaki, A.M.P., Lelarge, M.L.V. \& Guerra, T. 2006. Impacto Antropogênico no Arroio Sapucaia (RS): Aplicação de Balanço de Massas aos Fluxos Hidrogeoquímicos e Índices de Contaminação nos Sedimentos. Revista Brasileira de Recursos Hídricos, 11: 15 - 24.

Gonzaga, E.P., Santos, V.V. \& Nicácio, R.M. 2011. Análise do comportamento do NDVI e NDWI em períodos de diferentes intensidades pluviométricas no sertão alagoano. In: SIMPÓSIO BRASILEIRO DE SENSORIAMENTO REMOTO, 15., 2011, Curitiba. Anais... Curitiba. p. 1736 - 1743. Disponível em: <http://www.dsr. inpe.br/sbsr2011/files/p1632.pdf>. Acesso em: 03 jun. 2016.

Govaerts, B.\& Verhulst, N. 2010. The normalized difference vegetation index (NDVI) GreenSeeker ${ }^{\text {TM }}$ handheld sensor: Toward the integrated evaluation of crop management. Part A: Concepts and case studies. Mexico, CIMMYT. Disponível em: <http://repository.cimmyt. org/xmlui/bitstream/handle/10883/550/94192. pdf? sequence=1\&isAllowed=y $>$. Acesso em: $08 \mathrm{fev}$. 2016.

IBGE. Instituto Brasileiro de Geografia e Estatística. 2014. Características Gerais da População. Disponível em: < http://cidades.ibge.gov.br/xtras/perfil. php?codmun=430770 >. Acesso em: 05 mai. 2016.

Jackson, T.J., Chen, D., Cosh, M., Li, F., Anderson, M., Walthall, C., Doriaswamy, P. \& Hunt, R. 2004. Vegetation water content mapping using Landsat data derived normalized difference water index for corn and soybeans. Remote Sensing of Environment, 92: 475 - 472. Ji, L., Zhang, L. \& Wylie, B. 2009. Analysis of Dynamic 
Thresholds for the Normalized Difference Water Index. Photogrammetric Engineering \& Remote Sensing, 75(11): 1307-1317.

Londe, L.R., Coutinho, M.P., Gregório, L.T., Santos, L.B.L. \& Soriano, E. 2014. Desastres relacionados à água no Brasil: Perspectivas e recomendações. Ambiente \& Sociedade, 17(4): 133-152.

Lopes, F.B., Barbosa, C.C.F., Novo, E.M.L. de M., Andrade, E.M. \& Chaves, L.C.G. 2014. Modelagem da qualidade das águas a partir de sensoriamento remoto hiperespectral. Revista Brasileira de Engenharia Agrícola e Ambiental, 18(suplemento): 13-19.

McFeeters, S.K. 1996. The use of the Normalized Difference Water Index (NDWI) in the delineation of open water features. International Journal of Remote Sensing, 17(7): 1425-1432.

McFeeters, S.K. 2013. Using the Normalized Difference Water Index (NDWI) within a Geographic Information System to Detect Swimming Pools for Mosquito Abatement: A Practical Approach Stuart. Remote Sensing, 5(7): 3544-3561.

Morais, E.S. 2010. Evolução da planície de inundação e confluência do rio Ivaí e rio Paraná na região do Pontal do Tigre, Icaraíma - PR: Uma abordagem geomorfológica. Dissertação de mestrado. Programa de Pós-Graduação em Geografia, Universidade Estadual de Maringá.

Oliveira, G.G. 2007. Mapa de suscetibilidade a inundações da sub-bacia do arroio da areia, Porto Alegre/RS Porto Alegre, RS. 96 p. Monografia de conclusão do curso, Curso de Geografia, Instituto de Geociências, Universidade Federal do Rio Grande do Sul.

Oliveira, G.G., Penteado, A.F., Saldanha, D.L. \& Ross, J.S 2009. Mapeamento e análise da distribuição das áreas inundáveis na bacia do rio dos Sinos/RS. In: SIMPÓSIO BRASILEIRO DE SENSORIAMENTO REMOTO, 14., 2009, Natal. Anais... Natal. p. 4173 - 4180 Dispo-

Manuscrito 619

Editores: NIna Moura \& Paulo A. Souza. nível em: <http://www.dsr.inpe.br/sbsr2015/files/ p1352.pdf >. Acesso em: 29 nov. 2015.

Penteado, A.F., Petry, S.H. \& Ross. J.L.S. 2012. Riscos associados ao sistema de controle de enchente no vale do rio dos Sinos (RS - Brasil). Revista Territorium, 19: 161-168.

Re, M., Storto, L., M., Lecertua, E. \& Kazimierski, L. 2015. Anticipando la crecida: Inundaciones en La Ribera de Quilmes. Informe Instituto Nacional del Água, Buenos Aires, 69 p. Disponível em PDF no link: <http://ina.gov.ar/pdf/LH-AnticipandoLaCrecida_ Informe_12Mar2015.pdf>. Acesso em: 08 fev. 2016.

Reis, J.B.C. \& Saavedra, O.F.C. 2015. Comparação de métodos de classificação para reconhecimento de corpos d'água em imagens do sensor OLI do Landsat8. In: SIMPÓSIO BRASILEIRO DE SENSORIAMENTO REMOTO, 17,. 2009, João Pessoa-PB. Anais... João Pessoa, p. 59-66.

Rouse, J.W., Hass, R.H., Schell, J.A. \& Deering, D.W. 1973. Monitoring Vegetation Systems in the Great Plains with ERTS. In: EARTH RESOURCES TECHNOLOGY SATELLITE-1 THIRD ERTS SYMPOSIUN. Washington, D.C. p. $309-317$.

Saavedra, O.F.C., Muñoz, V.A. \& Reis, J.B.C. 2015. Delimitação da planície inundável e avaliação a partir de um evento de inundação ocorrido no município de São Borja (RS). In: SIMPÓSIO BRASILEIRO DE SENSORIAMENTO REMOTO, 17., 2015, João Pessoa. Anais... João Pessoa. p. 6290-6297. Disponível em: <http://www.dsr.inpe.br/sbsr2015/files/p1352. pdf $>$. Acesso em: 28 nov. 2015.

Sausen, T.M. \& Lacruz, M.S.P. 2015. Sensoriamento remoto para desastres. São Paulo, Oficina de textos, 288 p.

$\mathrm{Xu}, \mathrm{H} .2006$. Modification of normalised difference water index (NDWI) to enhance open water in remotely sensed imagery. International Journal of Remote Sensing, 27 (14): 3025-3033. 